\title{
ANALIZA DIMENZIONIRANJA FLEKSIBILNIH I KRUTIH KOLOVOZNIH KONSTRUKCIJA
}

Zahid Bašić ${ }^{1}$

Ahmet Mešanović ${ }^{2}$

УДК: 625.8

DOI:10.14415/konferencijaGFS 2015.050

Rezime: Ovim radom urađena su istraživanja dimenzioniranja kolovoznih konstrukcija, te provedena analiza rezultata istraživanja. U današnje vrijeme gdje je prisutno mnoštvo različitih materijala $i$ velika razlika u tržišnim cijenama koštanja izvedbe ovih radova, kod projektovanja novih i sanacije postojećih saobraćajnica zadržana je praksa da se pri dimenzioniranju koristi jedna od poznatih metoda, a ti rezultati dobiveni na taj način prihvataju se kao relevantni. Analizom je data uporedba dobivenih rezultata proračunima slojeva kolovozne konstrukcije, urađenih po priznatim metodama dimenzioniranja, kako za fleksibilne kolovozne konstrukcije, tako i za krute kolovozne konstrukcije. Prema rezultatima urađena je uporedba cijene koštanja jednog metra dužnog slojeva, te je izvršena uporedba cijene koštanja kolovozne konstrukcije po jednom metru dužnom, a uzimajući u obzir priznate metode dimenzioniranja. Krajni cilj ovog rada je uporedna analiza dimenzioniranja fleksibilnih $i$ krutih kolovoznih konstrukcija, te prijedlog najpovoljnije varijante kako za fleksibilne tako i za krute kolovozne konstrukcije.

Ključne reči: kolovozna konstrukcija, analiza, dimenzioniranje, metode

\section{UVOD}

Kako bi se odgovorilo zahtjevima vremena i uslova saobraćaja počinju se pojavljivati metode za dimenzioniranje kolovoznih konstrukcija. U početku su se pojavljivale najprostije metode koje prilikom proračuna uzimaju jako mali broj uticajnih parametara, a kasnije složenije koje u obzir uzimaju široki dijapazon uticajnih parametara Ovim istraživanjem sprovedena je optimizacija rješenja primjene krutih i fleksibilnih kolovoznih konstrukcija.[1] Ovim istraživanjima, a za poznate parametre,izvršeno dimenzioniranje kolovoznih konstrukcije kako krutih tako i fleksibilnih a prema poznatim metodama dimenzioniranja. Proveden je proračun po šest metoda dimenzioniranja fleksibilnih kolovoznih konstrukcija i osam metoda krutih kolovoznih konstrukcija. Ovom analizom je bitno bilo provjeriti dali je ispravna praksa kod

\footnotetext{
${ }^{1}$ Prof. Dr. sc. Zahid Bašić, dipl. ing. građ., Univerzitet u Tuzli, Rudarsko-geološko-građevinski fakultet, ul. Tihomila Markovića br. 1, 75000 Tuzla, mob.: 0038761136751, e-mail: mido_basic@hotmail.co.uk

${ }^{2}$ Ahmet Mešanović, dipl. ing. građ., «Tehno Plan» d.o.o. Kalesija, Ul. Žrtava genocida u Srebrenici br. 22, 75260 Kalesija
} 
projektovanja saobraćajnica, korištenje samo jedne metode,odnosno dali sve metode daju približno iste rezultate kako ukupne debljine kolovozne kontrukcije tako i debljina slojeva kolovozne konstrukcije. [1] Nakon provedene uporedne analize metoda dimenzioniranja kolovoznih konstrukcija, te nakon izbora najpovoljnije metode dimezioniranja, cilj je analiza najpovoljnih varijanti u smislu cijene koštanja radova. Treba napomenuti da je cijela analiza razmatrana na jednom metru dužnom saobraćajnice čije je ukupna širina 7,0 m tj saobraćajnica se sastoji od dvije saobraćajne trake od po 3,5 m što je i dato kao ulazni parametar provedenog proračuna. Analizom je utvrđeno, da je najoptimalnija metoda dimenzioniranja, metoda kojom dobivamo najmanju količinu utrošenog materijala a samim tim i cijenu koštanja.Takođe treba napomenuti da sve ove metode u obzir uzimaju različite ulazne paramatre,i da se kod izbora najpovoljnije varijante nije vodilo računa o ulaznim parametrima nego o već pomenutom utrošku materijala odnosno cijeni koštanja. [1] Kad je u pitanju konačan rezultat ovog istraživanja, odnosno izbor najoptimalnijeg rješenja tipa kolovozne konstrukcije, uzet je u obzir utrošak materijala i na osnovu njega jedinična cijena koja je dala mogućnost poređenja jedne i druge kolovozne konstrukcije.

\section{UPOREDNA ANALIZA REZULTATA DIMENZIONIRANJA FLEKSIBILNIH KOLOVOZNIH KONSTRUKCIJA}

$\mathrm{Na}$ slici 1. je prikazana uporedna analiza debljina habajućeg sloja dobivenih po pomenutim metodama dimezioniranja.Sa dijagrama se može zaključiti da su metode po Smjernicama,metoda Colorado, Ajhornova metoda i AASHTO dale iste rezultate tj debljinu $\mathrm{d}=4,0 \mathrm{~cm}$ kad je u pitanju habajući sloj .Debljinom odstupaju metoda Shooka i Finna sa debljinom $d=5,0 \mathrm{~cm}$ i CBR metoda sa debljinom habajućeg sloja d=7,0 cm. [1]
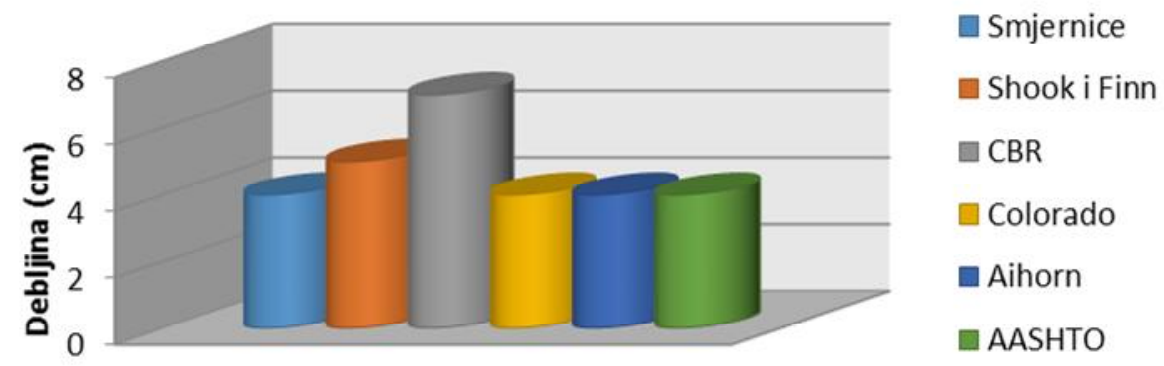

Slika 1.Uporedba debljina habajućeg sloja dobivenih po metodama dimenzioniranja fleksibilnih kolovoznih konstrukcija

$\mathrm{Na}$ slici 2. je prikazana uporedna analiza debljina bitonosivog sloja dobivenih po pomenutim metodama dimezioniranja.Sa dijagrama se može zaključiti da metode gotovo isto ako i kod habajućeg sloja daju sljedeće rezultate;metoda po Smjernicama,metoda Colorado,Ajhornova metoda i AASHTO su dale iste rezultate tj debljinu d $=8,0 \mathrm{~cm}$ kad je u pitanju habajući sloj .Debljinom odstupaju metoda Shooka i Finna i CBR metoda sa debljinom $\mathrm{d}=10,0 \mathrm{~cm}$ [1] [2] [3]

\section{4}




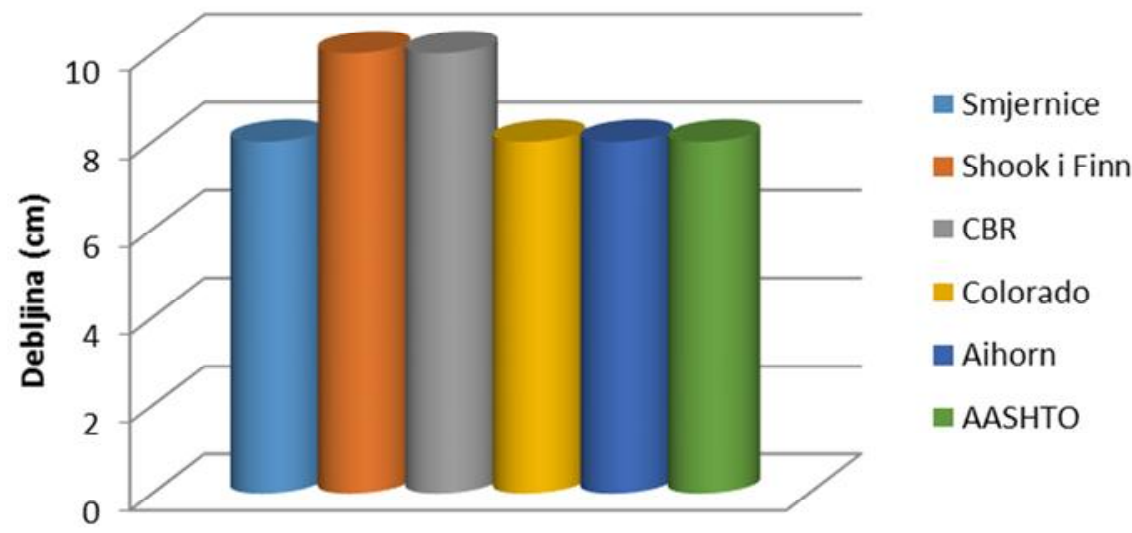

Slika 2.Uporedba debljina bitonosivog sloja dobivenih po metodama dimenzioniranja fleksibilnih kolovoznih konstrukcija

Na slici 3. je prikazan dijagram koji predstavlja djelimični cilj ovog rada, naime, na slici je prikazana uporedna analiza cijena koštanja $1 \mathrm{~m}^{1}$ kolovozne kontrukcije koja se sastoji od dvije saobraćajne trake širine $3,5 \mathrm{~m}$ dobivene po već pomenutim metodama dimenzioniranja.Sa pomenutog dijagrama se može vidjeti da je metoda Colorado dala najbolje rezultate odnosno cijenu od $89,5 \mathrm{KM} / \boldsymbol{m}^{1}$ kolovozne konstrukcije.Najgore rezultate pokazala je CBR metoda sa jediničnom cijenom od $196,3 \mathrm{KM} / \mathrm{m}^{1}$. Cijene koštanja metra dužnog kolovozne konstrukcije dobivenih po ostalim metodama dimenzioniranja moguće je očitati sa prikazanog dijagrama na slici 4.9. [1] [3]

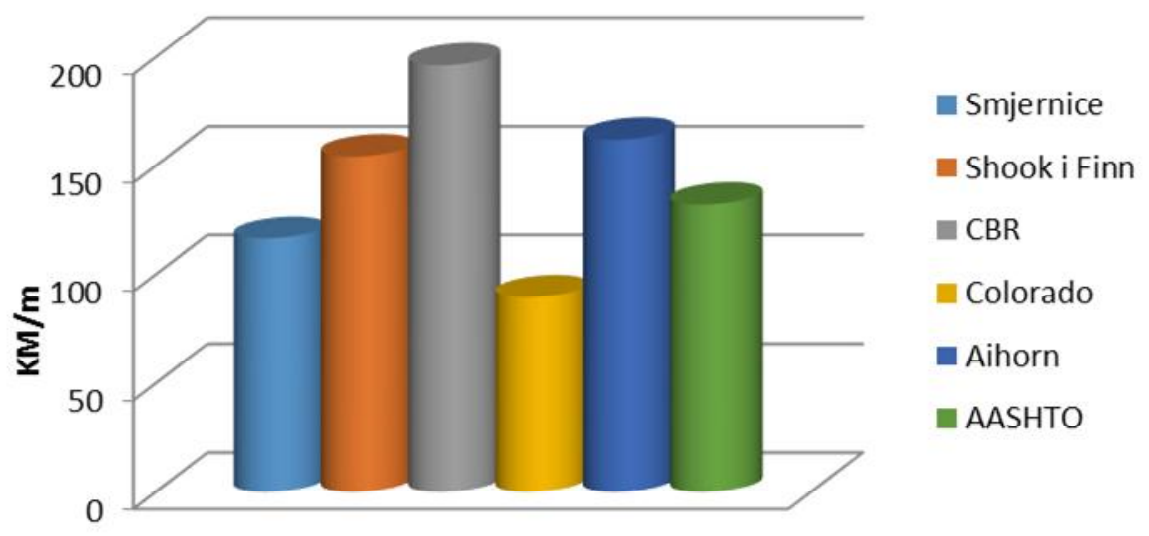

Slika 3. Uporedba cijene koštanja metoda dimenzioniranja fleksibilnih kolovoznih konstrukcija 
International conference

Contemporary achievements in civil engineering 24. April 2015. Subotica, SERBIA

\section{UPOREDNA ANALIZA REZULTATA DIMENZIONIRANJA KRUTIH KOLOVOZNIH KONSTRUKCIJA}

$\mathrm{Na}$ slici 4. je prikazana uporedna analiza debljina betonske ploče dobivene po pomenutim metodama dimezioniranja krutih kolovoznih konstrukcija.Sa dijagrama se može zaključiti da metoda Američkog inžinjerskog korpusa daje najbolje rezultate debljine betonske ploče tj. Debljinu od $\mathrm{d}=13 \mathrm{~cm}$,najgore rezultate je pokazala važeća metoda data u smjernicama i metoda Piketta i Reya.

Na slici 4.11 je prikazana uporedna analiza debljina gornjeg nosivog sloja dobivenih po pomenutim metodama dimezioniranja krutih kolovoznih konstrukcija.Sa dijagrama se može zaključiti da Engleska metoda daje najbolje rezultate debljine gornjeg nosivog sloja tj. Debljinu od $\mathrm{d}=12 \mathrm{~cm}$,dok sve ostale metode daju identične rezultate tj debljinu od $\mathrm{d}=20 \mathrm{~cm}$. [1] [2]

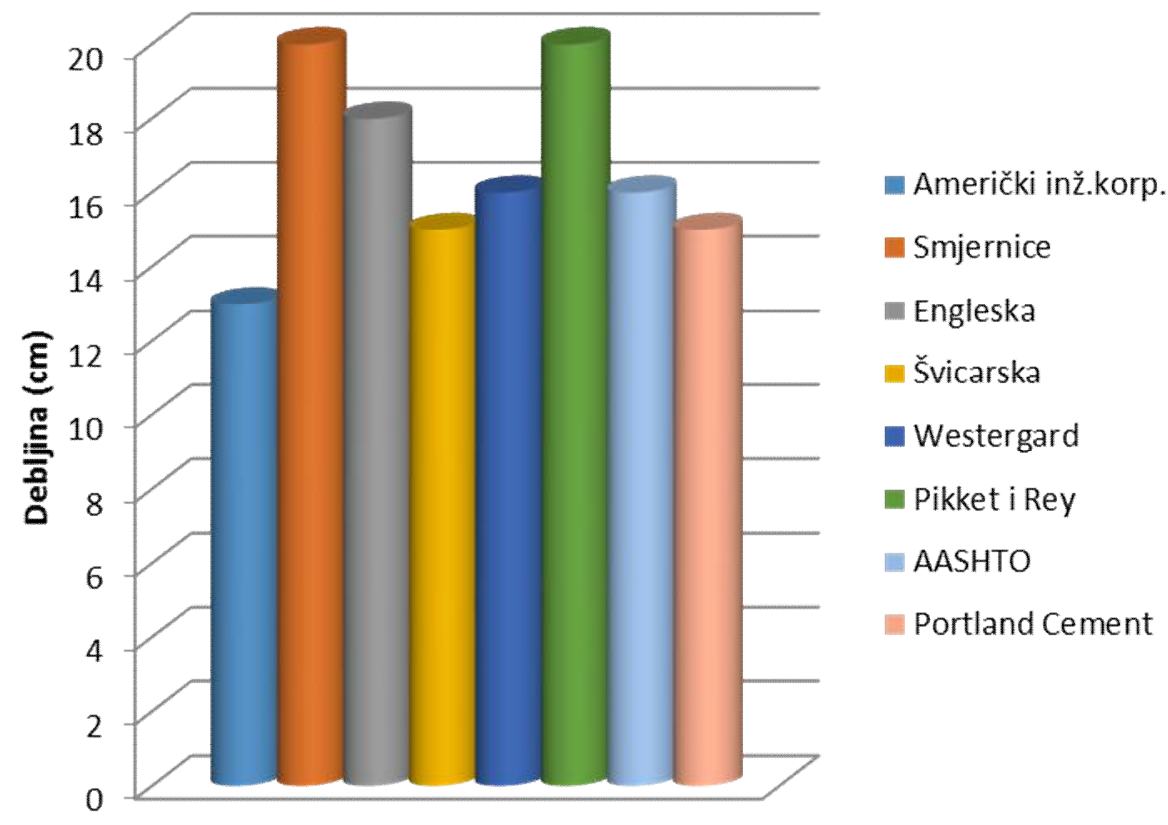

Slika 4.Uporedba debljina betonske ploče dobivene po metodama dimenzioniranja krutih kolovoznih konstrukcija

I konačno na slici 5. je prikazana uporedna analiza cijene koštanja konstrukcije dobivene po metodama dimenzioniranja krutih kolovoznih konstrukcija.Sa dijarama se može zaključiti da najbolju cijenu daje metoda Američkog korpusa sa vrijednošću od 178,84 $\boldsymbol{K} \boldsymbol{M} / \boldsymbol{m}^{1}$. Najlošiju cijenu daje važeća metoda data u smjernicama sa jediničnom 
Међународна конференција

Савремена достигнућа у грађевинарству 24. април 2015. Суботица, СРБИЈА

vrijednošću od $224 \mathrm{KM} / \mathrm{m}^{1}$. Vrijednosti ostalih metoda dimenzioniranaj moguće je očitati sa dijagrama na slici 4.16

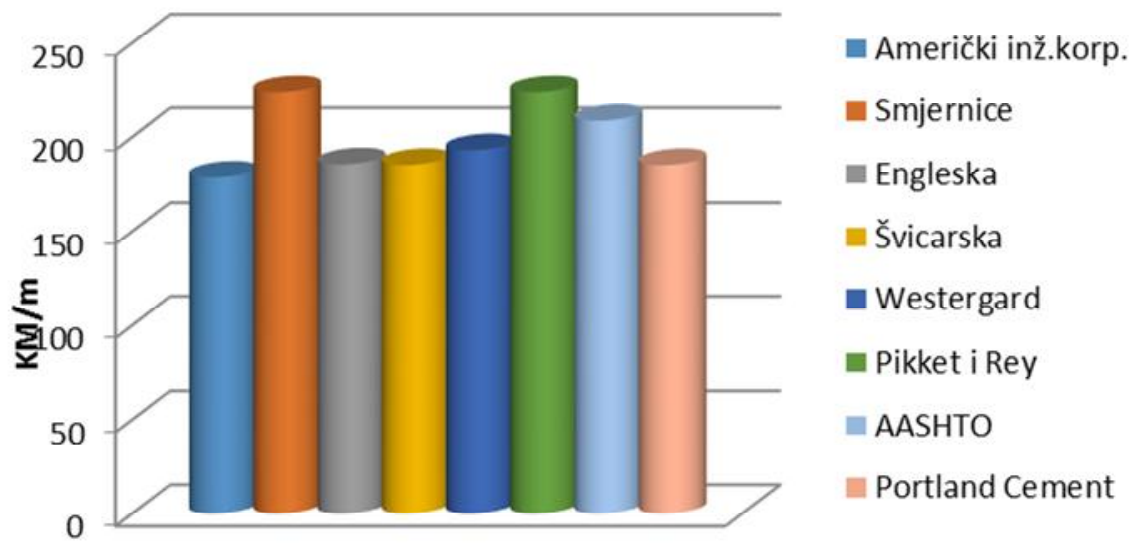

Slika 5. Uporedba cijene koštanja metoda dimenzioniranja Krutih kolovoznih konstrukcija

\section{UPOREDNA ANALIZA REZULTATA DIMENZIONIRANJA FLEKSIBILNIH I KRUTIH KOLOVOZNIH KONSTRUKCIJA}

Sa dijagrama prikazanog na slici 6. može se zaključiti da je fleksibilna kolovozna konstrukcija sa cijenom od $89,55 \mathrm{KM} / \mathrm{m}^{1}$,znatno jeftinija od krute kolovozne konstrukcije,čija je cijena uz iste ulazne parametre $178,84 \mathrm{KM} / \mathrm{m}^{1}$.

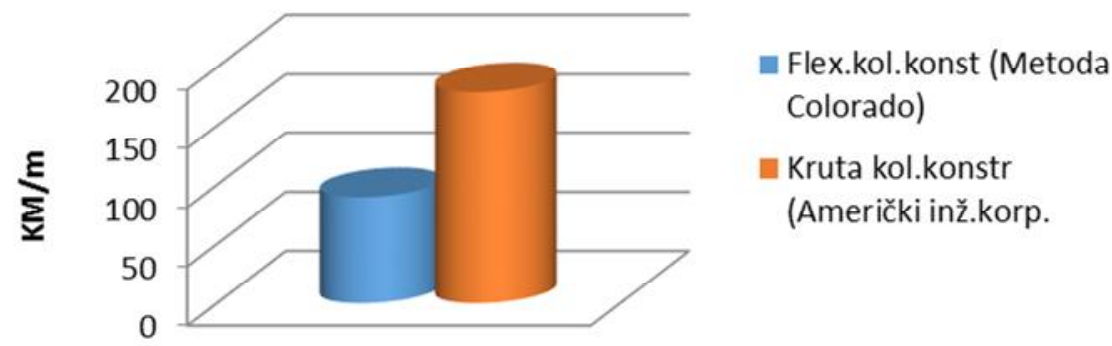

Slika 6. Uporedba cijene koštanja fleksibilne i krute kolovozne konstrukcije

\section{ZAKLJUČAK}

Provedenim istraživanjima je izvršena optimizacija rješenja primjene krutih i fleksibilnih kolovoznih konstrukcija saobraćajnica. 
Na konkretnoj lokaciji za koju su urađeni uticajni parametri, izvršeno je dimenzioniranje kolovozne konstrukcije, fleksibilne $i$ krute, a prema poznatim metodama dimenzioniranja i izvršena analiza. Proveden je proračun po šest metoda dimenzioniranja fleksibilnih kolovoznih konstrukcija i osam metoda krutih kolovoznih konstrukcija, te urađena analiza. Obzirom na prvobitni cilj izbor metode dimenzioniranja koja daja nepovoljnije rezulatate,pokazalo se da kod fleksibilnih kolovoznih konstrukcija gledano sa ekonomske strane najbolje rezultate daje Metoda Colorado sa jediničnom cijenom od $89,55 \mathrm{KM} / \mathrm{m}^{1}$. Kada su u pitanju krute kolovozne konstrukcije najbolje rezultate je pokazala metoda Metoda Američkog inžinjerskog korpusa sa jediničnom cijenom od 178,84 KM/m². Ovi dobiveni podaci su poslušila kao osnova za dobivanje krajnjeg rezulatat ovog rada. Nakon provedene analize zaključeno je da je fleksibilna kolovozna konstrukcija znatno povoljnija od krute kolovozne konstrukcije sa jediničnom cijenom od $89,55 \mathrm{KM} / \mathrm{m}^{1}$, za razliku od krute čija je dobivena cijena iznosila $178,84 \mathrm{KM} / \mathrm{m}^{1}$. Kao konačan rezultat ovog istraživanja, odnosno analize tipa kolovozne konstrukcije, uzet je u obzir utrošak materijala i na osnovu njega jedinična cijena koja je dala mogućnost poređenja jedne i druge kolovozne konstrukcije.

\title{
LITERATURA
}

[1] Mešanović A. Optimizacija rješenja primjene krutih i fleksibilnih kolovoznih konstrukcija gradskih saobraćajnica Univerzitet u Tuzli, Tuzla, 2009.

[2] Bašić Z. Putevi, izdavačka kuća OFF-SET Tuzla, Tuzla, 2014.

[3] B. Mazić, Asfaltne kolovozne konstrukcije, Građevinski fakultet Univerziteta u Sarajevu, Sarajevo, 2007.

\section{ANALYSIS OF DIMENSIONING FLEXIBLE AND SOLID PAVEMENT STRUCTURES}

\begin{abstract}
Summary: This work was done the research dimensioning pavement structures, and the analysis of the research results. At the present time where there are a multitude of different materials and a large difference in market prices, cost performance of these works, in the design of new and rehabilitation of existing roads maintained a practice that is used when sizing one of the known methods, and these results were obtained in this way are accepted as relevant. The analysis of the data comparing the results obtained budgets pavement layers, performed by recognized methods of dimensioning, both for flexible pavement, and for rigid pavement. According to the results presented comparing the cost price of one meter of due layers, and made comparisons cost pavement per linear meter, taking into account the recognized method of sizing. The ultimate goal of this study is a comparative analysis dimensioning of flexible and rigid pavements, and a proposal for the best variant for both flexible and rigid pavement for.
\end{abstract}

Keywords: pavement, analysis, dimensioning, methods 